\title{
Examining the legislative and institutional framework for special units in Cyprus
}

\section{Charalampous Constantia, Papademetriou Christos}

\begin{abstract}
This paper aims at examining the institutional framework within which Special Units (SUs) in Cypriot secondary education operate. The establishment of SU targets to facilitate the education of pupils defined as having special educational needs (SEN) in mainstream schools, and their operation is governed by the 1999 law and subsequent amending acts and circulars. Neither the operation of the SUs and the institutional framework that guides their operation have yet been investigated. The main aim of our research was to investigate teachers' and parents' views of the way in which SUs function, as well as their opinions of the legislative sections relating to the special units. This process led to the creation of a critical approach called the Institutional Framework for Special Units in Cyprus. Lastly, the participants were asked to propose ways in which the SUs could operate an inclusive environment. This paper presents qualitative research conducted in three secondary schools in Cyprus. Our sample consisted of 52 participants (heads, special education associate administrators, assistant heads, teachers, parents) over a five month timespan (September 2017-February 2018). The results lead to the conclusion that immediate action for further improvement and change is imperative, primarily for the benefit of pupils defined as having SEN.
\end{abstract}

Keywords: special units, inclusive education, institutional framework for special units

\section{Introduction}

In recent years, there has been a cross-national discussion among researchers and policy makers about ways to prevent the marginalization of pupils defined as having SEN (Messiou, 2016; Szeto, Brydges, Mkandawire, 
2018). It can be described as a positive move towards the implementation of an "inclusive education" policy; a notion that encourages an embracing educational system, in which pupils defined as having SEN have an equal opportunity to be educated and participate alongside their peers in school life, in mainstream schools (Messiou, 2016). In essence, the term refers to pupils' right to attend a mainstream school, regardless of how they may differ from what is perceived as "normal" (Ainscow, Booth, Dyson, 2006a).

Many European countries, including Cyprus have followed this policy (Manzano-García, Fernández, 2016). For example, both Greece - according to Soulis, Georgiou, Dimoula and Rapti (2016) - and Italy - according to Anastasiou, Kauffman and Di Nuovo (2015) - promote Education for All (United Nations Educational, 2005) by following a one-way approach. This means that mainstream education institutions are responsible for promoting inclusive education (European Agency for Development in Special Needs Education, (EADSNE) 2007) and for incorporating pupils defined as having SEN into mainstream schools (Priyanka, Samia, 2018; Timothy, Agbenyega, 2018). But this view could be described as inaccurate, since at least in Greece in 2018-2019, the Greek statistics indicated that students with disabilities and/or special education needs attended "special schools", or "pull-out programs/resource units", or received "within the classroom without additional support" instruction or were placed "in the regular class with shadow teaching/parallel support" (European Commission, 2018). This does not seem to be a "one-way approach".

In the case of Cyprus, as set out in the 2001 regulation (N. 69(I)/2001), mainstream classes include all local children, including those pupils defined as having SEN (Charalampous, Papademetriou, 2020). This regulation, is an attempt to identifyand overcome the obstacles that all pupils face in learning and participate in education, regardless of their socioeconomic background, ethnicity, or academic performance (Angelides, Avraamidou, 2010).

Conversely, a two-track approach can be found in educational policy in Switzerland and Belgium, where pupils defined as having SEN are educated in special schools or classes (EADSNE, 2007). On the other hand, there are countries, such as the United Kingdom (Blackburn, 2016), France, Poland, Finland, and Ireland that follow a multi-track approach, with a variety of services and choices between mainstream and special education (EADSNE, 2007). 
Studying these different approaches, we find that, on the one hand, countries following a two-track or multi-track approach, recognize that are difficulties associated with a system of total inclusion. On the other hand, one cannot be sure that countries following a one-way approach, succeed in using inclusive practices, since implementation is dependent on the individual school (Holmberg, Jeyaprathaban, 2016).

The different approaches adopted by the abovementioned countries, as well as the varying opinions in the scholarly literature, indicate that while the debate on inclusive education has been ongoing for many years (Greenberg and Greenberg, 2016; Hornby, 2017, Vasiliadou, Symeonidou, 2017), it is far from settled. The practical application of inclusion in the school environment is often hindered by a range of obstacles (Charalampous, Papademetriou, 2019a), which can be seen in value, power, practical, and psychological barriers (Suleymanov, 2015). This observation led Ainscow (2005) to argue that inclusive education is one of the most important issues in education globally - when effective, inclusive education can eliminate social exclusion and contribute to the development of school systems in general (Ainscow, Booth and Dyson, 2006b). Co-teaching (Strogilos, KingSears, 2018) and differentiated instruction can contribute to the creation of an inclusive school environment for all pupils (Strogilos, 2018).

According to Charalampous and Papademetriou (2019b) the main piece of legislation that applies to inclusive education in Cyprus is the Law regarding the Education of Children with Special Needs of 1999 (N.113(I)/99). Subsequent amendments to the legislation were passed in 2001 (N.69(I)/2001), as well as a circular in 2013 (416/2013), an amendment in 2014 (N.87(I)/2014) and another circular in 2017 (7.16.07/17). Under the 1999 law, the Ministry of Education made its first proper attempt at tackling the issue of educating pupils defined as having SEN in mainstream primary and secondary schools.

The legislation supported the 'integration' of pupils defined as having SEN into the mainstream school, through full-day instruction in a special education classroom (known as an SU in Cyprus) and mainstream class placements for short periods of time (McCarthy, 2006). In this way, the Cypriot Ministry of Education sought to integrate pupils defined as having SEN (via the creation of SUs) by making minimal changes to the established structure and curricula of the educational system.

Subsequent amendments to the legislation were implemented in 2001, 2013, 2014, and 2017. An analysis of these institutional amendments and 
observations made in the school environment indicates that despite efforts to make the educational system inclusive, Cyprus has veered towards integration instead (Symeonidou, Phtiaka, 2009). At this point, we must clarify the difference between 'integration' and 'inclusion' - the former concerns the legislation and the latter the desired education system (Papademetriou, Charalampous, 2020). Integration brings pupils defined as having SEN into the existing system by creating separate but parallel curricula, with minimum overlap and without challenging the mainstream framework (Thomazet, 2009). On the other hand, inclusive education requires the restructuring of traditional education systems so that children at all levels of ability can learn alongside each other in mainstream classrooms (Symeonidou, Phtiaka, 2009).

The legislation, therefore, reflects a mindset which needs to be reassessed (Symeonidou, 2015), especially if the state truly wishes to work toward a system of inclusive education. Policy makers and scholars need to consider the existing national institutional framework and reflect on the progress made in education in recent years. A good starting point is to examine and redefine the SUs and examine the operation and effectiveness of Cyprus' educational system.

\section{Special Units and Inclusive Education}

One cannot assume that placement on its own is an indication of inclusion, as Haug (2017) illustrates. McMaster (2014) suggests, based on a review of qualitative studies by inclusive schools, that the existence of an SU may mean that no disability can prevent daily attendance at school. SUs offer great potential for the promotion of inclusion. The way in which an SU is used and arranged determines whether it offers inclusion or segregation (Greenstein, 2014). Inclusion is not only about the position of the students, but also about the level of involvement. The development of an equitable education system entails the identification and removal of obstacles. As many studies have shown (e.g. Kugelmass (2006), Paliokosta-Blandford (2010)), establishing an inclusive school setting not only provides social, legislative, and institutional structures, but also encourages collective community-conscious initiatives (teachers, parents, pupils) that lead to an inclusive culture and a welcoming and collaborative atmosphere intentionally created to promote the pursuit of deep-rooted learning.

The SUs were set up as part of efforts by the Cyprus Ministry of Education to create a mechanism for integrating pupils into the Cyprus education 
system. In compliance with the 1999 legislation and the 2001 regulation on the education of children with special needs, SUs should work toward integration into 'regular' schools, working in convenient and open places for children with special needs. The number of children attending an SU is set by the Ministry of Education and Culture of Cyprus and typically varies from two to eight children per team. There may be more than one team in a school. Children may be admitted to an SU once a request has been filed by a parent or teacher The request is then reviewed by a multidisciplinary team (school head, assistant head, special education liaison officer, counselor, parents). Students enrolled in the SU follow a detailed schedule created by the school administration with the assistance of the special education liaison officer, the assistant headmaster and the school's career guidance counselor. The 2013 circular stipulates that the schedule has to be approved by the Special Office for Secondary Education. It also states that these children are to be issued with a certificate of attendance twice a year. The certificate classifies the child's performance as "good," "very good" or "excellent" based on their academic success in the SU class.

In theory, and as has been argued by the Commissioner for the Protection of the Rights of Children (2011), the Cypriot educational system supports inclusion and aims at overcoming marginalization. In accordance with this official position, some scholars, such as Kasides, Apostolidou and Doufexi (2015), have argued that a system that makes use of SUs is implementing a type of inclusion. However, to be able to assess the character of the system, we need to have a closer look at the operation of the SUs in the school environment and what they offer the pupils involved.

According to the 2001 regulation, SUs should aim toward integration and inclusion in mainstream schools, operating in comfortable and accessible places for pupils defined as having SEN. The head of the mainstream school in which the SU is housed is responsible for its operation.

Most of the pupils defined as having SEN in Cyprus attend mainstream schools. Statistics on the Cypriot educational system show that there are only eleven special schools in Cyprus, with 411 pupils in total (Statistical Services, 2018). As a result, mainstream schools must respond to the challenges of implementing inclusive education, following the EADSNE (2007) guidelines (Symeonidou, 2018). The SUs have to follow a variety of measures to ensure the inclusion of pupils defined as having SEN, such as a flexible curriculum, easily accessible school buildings, tailored teaching styles and assessments, and staff that are trained to carry out the required inclusive 
practices (Symeonidou, Phtiaka, 2009). Additional EADSNE requirements are that SU pupils must follow the same routine as the rest of the pupils and have equal opportunities to participate in all aspects of school life (EADSNE 2007). All this can be promoted by differentiation in instruction in mainstream classes and general participation in all school activities.

As Symeonidou and Phtiaka (2009) mention, the main criticism of the current education system in Cyprus is that the school administration does not in fact follow EADSNE's guidelines (2007) on the inclusion of pupils attending SUs in mainstream classes. SU pupils are mostly confined to the special education classrooms. By contrast, in most European public schools SUs follow a structured and responsive curriculum that is designed to meet the educational needs of the children (Anastasiou, et al., 2015).

Special education on the island has often been portrayed as a pragmatic solution, first implemented in the 1970s, as a response to the issue of educating pupils defined as having SEN (Warnock, 2005). In the absence of major structural adjustments and without a comprehensive and inclusive curriculum, special education in Cyprus needs to be re-evaluated with a mind to pursuing substantial reforms and modernization to reflect current European standards.

The reform and modernization processes should target all the layers affecting decision-making and policy implementation, at the institutional, ministerial, school, and individual teacher levels. Pieridou and Phtiaka (2013) argued that pupils defined as having SEN are marginalized through the enforced legislation. Considering this argument, it is crucial to tackle the institutional framework regulating the SUs (Damianidou, Phtiaka, 2017).

From the above we conclude that SUs are self-contained classrooms. Therefore, the present division cannot lead to inclusion. The question is, however, how can we limit the marginalization felt by SU pupils.

\section{Methodology}

As already argued, SUs have to be investigated more systematically if we are to address the difficulties of achieving a less marginalizing education and draw conclusions about the progress achieved and type of changes that should be made for further improvement. We have already briefly referred to the foundational issue, i.e. the legislative framework under which the SUs 
operate; indeed, identifying its limitations and progress is the core aim of this research paper.

Having studied the legislative framework, our opinion is that it cannot be considered inclusive, as it forces students identified as having SEN to be segregated most of the day in the SU, depriving them of the right to believe that they are members of the school organization.

The main objective of our research was to convey teachers' and parents' beliefs about how SUs function, as well as their views on various legislative clauses and SUs. Another research goal was to use the data to illustrate the criticism of the legislative system. This process led to a crucial solution called the Institutional Framework for Special Units in Cyprus. The paper deals with two key points of the investigation (research questions):

(a) the degree to which legislative changes, the institutional structure regulating the functioning of SUs and their practical consequences prevent the marginalization of pupils identified as having SEN; and b) those aspects of the legislative changes, the institutional framework and their practical implications that should be considered as deficient in preventing marginalization.

For the purpose of this research, a qualitative methodology approach was selected, because we believe that it offers an opportunity to critically assess teachers' views of the current institutional framework. Participants were involved in discussions to express their views on the relevant institutional framework. This brought greater clarity on how the institutional framework is applied to secondary education and whether it is in line with the principles of inclusive education.

The qualitative data was analyzed using a critical theory approach. Critical theory is a qualitative methodology that aims to explain how "educational concepts, policies and behaviors help shape human consciousness forms and how they contribute to wider political and ideological viewpoints and social realities" (Beyer, 2001, p.153). According to Tilley (2019, p.159) critical theory is "necessary to explore the experiences of individuals and groups who have faced marginalization and inequitable treatment within educational systems and to critique the policies and procedures in place".

We therefore conducted an exploratory study with the aim of gaining an understanding of the problems with the SU system and to record and com- 
prehend opinions and rationales. The research was conducted in three secondary schools (pupils were aged 12 to 18 years old) with an SU. Firstly, we conducted a pilot interview with a sample of 5 teacher-participants in a single school. The pilot study was followed by interviews. The teachers that were selected as participants had all taught in an SU or in a mainstream class that included pupils from an SU. The parents that were selected to be participants were parents of pupils defined as having SEN. Only two special education associate administrators were included in this study. These were Ministry representatives who oversee the operation of SUs. They supervise any special education issues arising at approximately four or five schools. Our final sample consisted of 52 participants (Table 1). The results of the pilot study are included in the final data analysis. The study was conducted over a two-month span (October 2017-December 2018). The criterion for selecting the participants was their interaction with pupils defined as having SEN.

Table 1 Study participants

\begin{tabular}{|l|c|c|c|c|}
\hline Participants & School 1 & School 2 & School 3 & Total \\
\hline Heads & 1 & 1 & 1 & $\mathbf{3}$ \\
\hline Special education associate administrators & 1 & 1 & 1 & $\mathbf{3}$ \\
\hline Assistant heads & 3 & 3 & 4 & $\mathbf{1 0}$ \\
\hline Teachers & 8 & 9 & 7 & $\mathbf{2 4}$ \\
\hline Parents & 5 & 3 & 4 & $\mathbf{1 2}$ \\
\hline Total & $\mathbf{1 8}$ & $\mathbf{1 7}$ & $\mathbf{1 7}$ & $\mathbf{5 2}$ \\
\hline
\end{tabular}

During the data analysis, the main reoccurring themes that emerged were: a) the SU's purpose, b) the teaching periods in a mainstream class for pupils defined as having SEN, c) teachers' qualifications, d) the assistant head's responsibilities, and e) opinions about the "Certificate of Attendance".

Qualitative approach allowed participants to freely express their views on the law regarding the operation of SUs and hence reveal any strengths and weaknesses. It led to constructive suggestions as to how the environment could be made less marginalizing. Participants were encouraged to express their views on the relevant legislation. The interviews, which consisted of questions such as: "Do you think that the institutional framework promotes inclusion?", "What aspects do you regard as inclusive and as marginalizing?","Could you analyze the roles of the key stakeholders in the operation of the SUs? ", allowed us to critically assess those views, showing how the abovementioned 
2013 and 2017 circulars are applied to secondary education and whether that is in line with the principles of inclusive education.

In addition to the interviews, we conducted observations (about 8-10 in each school) and a review of the institutional framework. The initial interviews were followed by attendance and participant observations in mainstream classes and SUs. Each observation lasted 40 to 45 minutes. Participants were informed about the nature of the research and this took approximately 10 minutes. The participants were asked to read the legislation carefully and express their views. After the classroom observations and legislation reviews, interviews were conducted to reveal the participants views on the observations. All data were recorded in audio and writing, to record and capture impressions, behaviors, and non-verbal cues, and to illustrate the environmental context, ensuring the validity and reliability of the research. Once the data had been collected and recorded, they were presented to the participants to be accepted and confirmed.

Our research design took into account ethical issues, data protection, and confidentiality standards. The participants provided voluntary informed consent and had the option of withdrawing from the research at any time. The researchers developed an authentic rapport with the participants by being present at the three schools, for approximately two hours a day, almost daily throughout the research period. Permission to conduct the study was obtained from the heads of all three schools and the parents of all the children involved. Confidentiality and anonymity were guaranteed, so all the names attributed to the quotes in this paper are pseudonyms.

\section{Analysis}

The research participants started by looking at the basic legislation of 1999 relating to special education in Cyprus. The 1999 legislation and accompanying regulations define SUs without providing a great deal of detail. However, it states that:

SU means a unit operating in a mainstream school for the provision of special education and training in accordance with the provisions of this Law (p.339).

Furthermore, it states that disabled children are prohibited from attending an SU in a mainstream school, except where in accordance with the provisions of the law. It also states that: 
The Minister shall ensure the establishment of SUs according to the needs arising from the evaluation reports issued by the Provincial Commission (p.346).

According to Nicolas, a teacher at School 1:

the 1999 law generally says what an SU is and that it is set up by the minister. He does not tell us how to teach children, nor how to behave.

The 2001 Special Education Modification Regulation states that: a) SU students are invited to attend schools in their neighborhood, b) the school head is responsible for its operation, c) the Special Tutoring and Education District Committee decides how many students attend an SU, d) the SU schedule must be the same as that for the mainstream class, except in exceptional cases, e) SU pupils are re-evaluated every two years. Under the 2014 amendment it is possible for SUs to operate in technical secondary schools.

The 2001 regulation includes a lot of additional information on the operation of SUs, making it much more inclusive than the 1999 legislation. However, when studying the 2013 and 2017 circulars, participants noticed that they were more informative than the earlier legislation and amendments.

Therefore, we turn our attention to a review and comparison of the 2013 and 2017 circulars. Both circulars state the objectives of the SU with regards to pupils defined as having SEN; these are to enhance self-confidence, socialization, emotional safety and the acquisition of skills that will help them in their future occupation and participation in society (2013 circular, 416/2013; 2017 circular, 7.16.07/17) circular). Thus, one of the main purposes of enabling secondary school pupils defined as having SEN to attend both mainstream and SU classes is to ensure a smooth transition from the school environment to the workplace.

While the objective seems clear enough, i.e. to assist pupils defined as having SEN in becoming fully functioning members of society, the policies put in place and the overall education system cannot be regarded as having achieved this objective. The system's main drawback, as we perceive it, is its inability to fully-integrate pupils defined as having SEN. Isolating pupils defined as having SEN in SUs for the majority of their school time, with only a few teaching periods per week in mainstream classes, cannot reinforce inclusion. This is what Maria, an assistant head at School 1, states: 
Although the objective of the SU is socialization, I see that what it achieves is marginalization

\section{Teaching qualifications}

A key disadvantage of the 2013 circular was that school staff were not required to have the professional qualifications to manage SUs, teach pupils defined as having SEN, and address any arising issues.

The 2013 circular stated in relation to the regulation of the SUs that:

the selection of teachers should be based on strict criteria to ensure the interests of special education pupils are safeguarded, to maximize the quality of the teaching periods. The selection should be carried out by the school's administration, in collaboration with the coordination administrator.

One can plainly see how the 2013 circular gave the heads leeway in selecting and allocating teachers to SUs as they saw fit, without providing any specialist guidance or specific criteria. It stipulated that SU teachers have to:

a) be characterised for their sensitivity to Special Needs and their interest in working with children with Special Needs; b) distinguished for their pedagogical philosophy and the belief that all children have the right to learn within a mainstream school and c) their relational and stimulating skills; d) training in education and their specific skills; e) effectiveness in teaching support lessons

These ambiguities in the regulations had an enormous effect on the desired end-result, i.e. pupil inclusion in the school environment, since both academic progress and social integration could be affected by the qualifications and personality of the teacher. According to Maria, a teacher at School 2:

These criteria simply existed. The headteachers decided who would teach in the SU without taking them into account. They just ask who wants to...

This problem was broadly acknowledged in our interviews, and in the scholarly literature. Inclusive education in Cyprus is mostly focused on teachers' attitudes (Damianidou, Phtiaka, 2017), policies and practices 
(Symeonidou, 2017a), which do not always promote the creation of inclusive school environments (Charalambous, Papademetriou, 2018). O'Connor, Yasik and Horner (2016) stressed the importance of providing teacher training on the legislation and special education policy. Critically, this could be considered a major defect in the Cypriot educational system (Symeonidou, Mavrou, 2013).

This issue was addressed recently in the 2017 circular, which includes an additional point on the qualifications required to teach in an SU:

Specialization in Special Needs (Masters or Degree in Special Education, Further Education/Seminar Training).

This is considered a positive development since the school head cannot simply choose who will teach in the SU.

Regarding this issue, a parent from School 3 said:

With the new circular we feel safer because we know that our children's teachers at least have the qualifications to teach our children, unlike previous years.

\section{Assistant head responsible for special education}

The 2013 circular also stated that there should be an assistant head responsible for the management and administration of the school's SU. In particular:

The school's principal, at the start of the school year, should appoint an Assistant Head responsible for Special Education. The aforementioned should be sensitized around the issue of special education and hold the relevant qualifications

However, in practice, there was no compulsory training or structured support given to the person in this role, let alone to those who teach in an $\mathrm{SU}$ on a day-to-day basis. As the primary criterion was the sensitization of the assistant head, it may be that the operation and efficacy of the SU was influenced by the personality and sensitivities of those managing it, rather than quantitative and tangible factors, such as professional qualifications and competences. The Ministry did not promote in-service training on inclusive education for assistant heads. Jack, a teacher at School 2, speaking about the duties of the assistant head, stated the following: 
It is a good thing that the head is obliged by law to assign responsibility to the assistant head for the education of children. The flaw is elsewhere... often, the assistant head does not have the skills or does not fulfil the requirements to adequately run an SU. There should be seminars and training ...Therefore, it ends up being the luck of the draw if the head and assistant heads are motivated to ensure the good operation of the $S U$.

This teacher felt strongly that the assistant head responsible for the operation of the SU should receive appropriate training for this role.

Fortunately, with the 2017 circular, this particular weakness in the institutional framework governing special education has been dealt with, at least theoretically. Specifically, the 2017 circular states that assistant heads responsible for the operation of an SU should have:

Pedagogical training (holder of a postgraduate diploma or undergraduate degree in Special Needs Education, Further Education/Seminar Training)

According to Anna, a special education associate administrator at School 2:

With the new circular, we know that the assistant head has at least attended some seminars. They will at least knows how we are supposed to work to help SU pupils.

This development ensures that the assistant head will have the necessary academic studies, qualifications, and skills to effectively operate an inclusive school, a requirement which should be clearly set out in the relevant legislation.

\section{Certificate of Attendance}

Another issue relating to the 2013 and 2017 circulars is the Certificate of Attendance. According to the 2013 and 2017 circulars, SU pupils are to be issued with a Certificate of Attendance every four months. It gives the following grades for attendance: "good", "very good", or "excellent". The academic performance of pupils in mainstream classes is not assessed at all. Mainstream pupils and pupils defined as having SEN are not assessed in a similar manner, as the former are assessed academically, while the latter are given a certificate for simply showing up to class. 
Helen, a SU teacher in School 3, has the following view:

...the discrepancy between the qualifications awarded to mainstream pupils and those attending SUs is a source of marginalization that must be discussed.

This particular issue, as Helen stated, contributes to the marginalization of SU pupils, who are often embarrassed about receiving a Certificate as it sets them apart from the other pupils who receive the Leaver's Certificate, which is an indication of achievement.

The difference in the school qualifications mainstream pupils and SU pupils receive should be considered more carefully. The "Certificate of Attendance" awarded to SU pupils puts them at a disadvantage, with regard to further academic, employment, financial, and social opportunities. While the aim behind the establishment and operation of SUs in mainstream schools is to integrate pupils defined as having SEN in the mainstream school environment and by extension in wider society, the qualification offered may stigmatize them in the next stages of their lives, as a marker of disability or as in many cases perceived inadequacy. This indicates that the entire process, from the design and operation of the SUs to the qualification offered, needs to be reassessed for the benefit of the pupils attending them. Moreover, public education and awareness could operate as a counterweight to social stigmas and discrimination. In this way, the marginalization would be addressed and tackled at two different levels: within and outside the school environment.

An incident that we witnessed at a school indicates the degree of marginalization encountered by pupils defined as having SEN and how it affects them at a personal level. One day, during breaktime, an SU pupil with cerebral palsy approached the teacher who was the head of the SU, with the help of her escort, and said:

Miss, can you place my report with the others' [mainstream pupils] reports. I'd prefer it if you didn't give it to me in the Unit.Can I tell my mum to come to the class and pick it up, just like it's done for the rest of the pupils? Do you mind if Mrs Eleni [mainstream class teacher] gives me my certificate instead of you?

It was evident from the beginning of our research that pupils defined as having SEN simply don't fit into the mainstream classes or the SUs; and 
their 'special' certificate is the ultimate, strong marker of this multilevel marginalization.

The only difference between the 2013 and 2017 circulars is that the latter includes another welfare aspect. Specifically, SU pupils wishing to get a Leaver's Certificate can take the subject examinations for all three classes at the gymnasium, lyceum, or technical school. In such cases, the Leaver's Certificate will record the grades for the four courses only. According to John, the head of School 3:

This seems to be less marginalizing for SU pupils, but it is also exhausting. This year we had an SU pupil who was in the third class. He wanted to get a Leaver's Certificate, so he was forced to take the exams for all the exam subjects for the three classes in one summer.

In essence, according to the 2017 circular, SU pupils have to choose between marginalization, represented by the "Certificate of Attendance", and exhaustion, since they need to pass exams that are not appropriate to their special educational needs in order to get the Leaver's Certificate.

The practical implications of having a less valued document becomes obvious once the SU pupil leaves school. The Certificate of Attendance, having no academic value, holds young people back by marking them as 'different' and consequently, less able, when they seek employment after graduation. Andreas, an assistant head at School 1, said:

The multipurpose meeting (mainstream and SU teacher, head, psychologist took part) included a progress evaluation for Anna (up to that point an SU pupil). After receiving positive feedback from the teachers regarding the pupil's progress, her mother expressed her wish that her daughter be considered a mainstream pupil from now on.

In studying the above case, we sense that there was a feeling of marginalization in the SU, but it also raises questions about what the options are for school leavers depending on the type of qualification and certificate they receive after graduation. Ioanna, a parent from School 3, expressed her concern about the matter thus:

Here, there is a dilemma. Should the child be educated in the SU? The law creates this problem as it does not clarify which type(s) of cases are to be included in the SU. I know many SU graduates who unfortunately 
were marginalized after graduation. The Certificate of Attendance is probably of no use. If a child joins the SU, then he or she is definitively educationally and socially marginalized?

\section{SU curriculum}

Another topic worth discussing is the SU curriculum, which is created by the school administration with the assistance of the Special Education Associate Administrators and the SU teacher. According to the instructions provided in the circular, SU pupils must be integrated in mainstream classes and taught according to their educational needs. According to both the 2013 and 2017 circulars:

When creating the SU curriculum, the parameters below must be strictly taken into account: a) Pupils must be integrated into a mainstream class for five to six teaching periods daily, b) during the exam sessions pupils must be removed for specific training in the SU class, which means that the pupils with special educational needs are forced to segregatewhen the mainstream pupils take exams, and c) pupils must attend lessons that promote their social and interpersonal skills, for example: Home Economics, Art, Music, Design and Technology, and Information Technology.

These subjects require fewer numeracy and literacy skills, and are therefore considered more appropriate for SU pupils. According to the 2013 circular:

The special education officer can tailor the curriculum according to each pupil's needs but, in general, SU classes should take up 32 hours per week. The pupils shall be taught Languages, Mathematics, Home Economics, Design and Technology, Information Technology, Art and Music.

As a result, SU pupils are integrated in the mainstream classes for only six teaching periods per week, in contrast to the five to six teaching periods daily stipulated in the circular. This clearly does not provide enough time for SU pupils to socialize with their mainstream peers.

This issue was dealt with in the 2017 circular, which states that the number of teaching periods and lessons in the SU is set by the Special Education Secondary Education Office in collaboration with the special education associate administrators, the educational psychologist and the 
special education group of each school, according to the specific needs of the pupils.

This positive change gives SU pupils the right to enjoy a personalized program according to their needs. This is a credible effort on the part of the Ministry, giving the student the right to at least some degree of inclusion.

Despite this positive aspect, there seems to be a negative side to the creation of personalized programs. Costas, a teacher, from School 2 said:

Every year we face a big issue with the SU. In order to be able to set up the curriculum, we have to integrate all the Unit children within one or two departments. Therefore, the Unit curriculum depends on the mainstream curriculum, so the SU teachers are restricted by the curriculum set by the mainstream classroom teachers. So...in this situation how can we create an individual curriculum for each pupil, based on their interests and potential? I know that it is not right to look at it this way, but in practice it is impossible. There are teachers who teach across two schools during the day.

So the problems that arise in relation to the creation of the personalized curriculum are not solely determined by the institutional framework, which operates at the theoretical level, but also by issues that are mainly related to the general practices followed by the Ministry.

Considering the findings of this research, it seems that the teachers may have the will and determination to create an inclusive system for pupils defined as having SEN but that there are manifold challenges in the existing educational system that prevent them from being resourceful. Teachers need to be empowered and supported through changes across the educational system if the malfunctioning practices are to be released from their standardized confines. Moreover the "one size fits all" mentality remains deeply rooted when it comes to curriculum design. This problem has been exacerbated by the recent economic crisis, which resulted in the underfunding of programs, significantly affecting the training of teaching staff in special education.

The lack of proper inclusion is even more evident among adolescent SU pupils after middle school. Their exposure to mainstream classes varies, for no discernible reason, depending on the type of high school/technical school that they choose to attend after leaving middle school. The process 
of creating individual curricula becomes even more difficult. This is because high schools have fewer overall hours of teaching than middle schools. In high school, pupils defined as having SEN attend lessons three days a week; these are split between the mainstream class and the SU, while for the remaining two days, they attend special educational programs outside of school.

The 2013 and 2017 circulars differ on this. According to the 2013 circular SU students spend 25 teaching hours per week in the SU and 10 hours per week in mainstream classes. According to the 2017 circular the withinschool program (number of teaching periods and lessons) is determined by the Special Education Secondary Education Office in collaboration with the special education associate administrators, the educational psychologist and the special education group of each school according to the specific needs of the pupils.

As Christos a parent from School 2 points out:

Now we feel better, since our child's timetable is being prepared by specialists who know our child and his particularities well.

We therefore reiterate that the 2017 circular comes one step closer to lessening the marginalization of SU pupils. At the same time, it strengthens efforts to provide individual programs for each pupil, while leading to decentralization and transferring responsibility for the creation of the individual program to people who personally know each pupil.

SUs also exist at technical schools; these are vocational secondary schools that offer job-specific training, covering fields such as hospitality and tourism, engineering, construction, hair and beauty services. The rationale behind the 2013 circular on the operation of SUs in technical schools is not always justifiable or clear. For example, pupils defined as having SEN choosing to study hospitality have to attend SU classes for a total of 32 teaching periods per week and attend mainstream classes for only four periods per week; if they choose hairdressing instead, they have to attend SU classes for 25 teaching periods per week, and only 10 teaching periods in mainstream classes.

The 2017 circular gave different approach considering the hairdressing program. It states that SU pupils are to be integrated on laboratory and technological courses in specially equipped workshops in the mainstream 
class, but there is no mention of the number of teaching periods they spend integrated in the mainstream class.

In practice, the secondary education system is the source of a great deal of confusion and concern amongst parents and pupils. This was evident in the interviews conducted in secondary schools. In one instance, in a joint interview with a pupil and his parents, when discussing the route that pupils should take after middle school, Costas a father from School 1, voiced the following concerns:

I do not understand ... I am sorry ... you have explained the system to me several times ... so if my son chooses to go to high school or do hairdressing at the technical school, he will join the mainstream class for more academic periods than if he chooses hospitality? How come? So, my son has to become a hairdresser in order to be more involved with other children that do not have any special needs? ... He likes to cook, so why can he not attend a school that offers cookery training? Basically, his enrolment in a hospitality program at a technical school will not offer anything more/different from a special school. In any case, he will stay in the SU. Are there any teachers with the necessary qualifications to help him?

These concerns were repeated in many of the interviews and reflect the inability of the system to include SU pupils in the school and broader social environment. According to the participant, the regulations and guidelines issued by the Ministry simply allow SU pupils to co-exist in the school with their peers but do not encourage inclusion and integration. This does not simply apply to middle school but, as the concerned parents and teachers said, is a phenomenon that affects the SU pupils in secondary school, and after graduation in their experiences of the outside world.

\section{Lack of detail and necessary guidance on inclusion}

Finally, both the 2013 and 2017 circulars lack detail and the necessary guidance. As Marios the head of School 2 said:

I cannot understand why the Ministry summarized all the regulations in a circular instead of issuing them in the form of proper legislation... Circulars are sent in bulk on a daily basis. We read most of them but in a rushed manner. Surely, the Ministry has to provide better guidance on the operation of SUs. 
By taking into consideration the above quotation we can say that the operation of SUs is essential to be governed by comprehensive principles and standards set by the European Union (EU), rather than circulars. As an EU member, Cyprus has to comply with the rules set by the EU. Additionally, the centralized educational system leaves little room for flexible decisionmaking by the teachers. The Ministry should, therefore, issue the SUs with clearer and more specific instructions and provide the framework, where appropriate, for teachers to create less marginalizing environments within their schools. During the same discussion, Anna, a teacher at School 3, expressed the following opinion:

We are being encouraged to combat "marginalization". But I wonder... Does the Ministry follow inclusive practices? The children are placed in a mainstream classroom only once a day. They have to be there for almost the whole day, but in that case, the Ministry has to provide the guidance and formalize different ways of teaching to avoid marginalization.

In essence, one can question whether Cypriot public schools really provide an "inclusive education"; in many cases pupils defined as having SEN are only taught in mainstream classrooms for some periods per day. Given this it is extremely difficult for pupils defined as having SEN to develop meaningful social relations with their school peers. Therefore, it is imperative that immediate action is taken and that the circular governing the operation of SUs is subjected to a careful evaluation and revision, and by extension the educational system. The evaluation and reforms will need to be conducted with good attention to detail and considering the state-of-the-art research in special education.

For inclusion to function properly, clear goals must be pre-defined and realistic practices proposed. While, internationally, the focus has been on the creation of inclusive school environments, the term "inclusion" is not mentioned at all in any of the institutional documents under study. The lack of reference to the term 'inclusion', in both the 1999 law and the 2001 regulation, especially given that the educational system claims to be inclusive, at its core, is a huge failing, for both the law and the regulation. The same applies to the 2013 and 2017 circulars, which are supposed to be the key institutional tools for educational professionals. This lack of reference to inclusion in these institutional documents can be considered evidence of the inability of the Cypriot educational system to become more inclusive in its practices. 


\section{Discussion}

Completing the research process, we concluded that SUs are segregative both in nature and structure. Approaching SUs from an inclusive perspective, we have attempted to compare the 2013 and 2017 circulars and have identified the ways in which the 2017 circular is less marginalizing for SU pupils. We have also identified weak points and areas for improvement, regarding the operation of SUs. In conducting the above analysis, and through our attempts to ascertain whether "the extent to which the legislative changes, the institutional framework governing the operation of SUs, and their implications in practice prevent the marginalization of pupils defined as having SEN" (research question 1), we have concluded that SUs promote integration despite inclusion. This phenomenon applies to the SU pupils as well and gradually leads to their marginalization (Damianidou, Phtiaka, 2017). Both the legislative and institutional framework therefore need rethinking (Symeonidou, 2015).

A key research finding is that the institutional framework does provide some guidance as to the operation of SUs in Cyprus secondary schools, such as specifying the role of the assistant head and teachers' specialization in special education. The results lead us to the conclusion that it is imperative immediate action is taken to ensure further improvement and change, primarily for the benefit of pupils defined as having SEN.

The main idea emerging from the research is that the 2017 circular helps reduce the marginalization of SU pupils, which promotes a bottom-up review (Ainscow, Dyson, Goldrick, West, 2016), taking into account the views of teaching staff that deal with pupils defined as having SEN on a daily basis.

Furthermore, we attempted to identify the legislative changes, the institutional framework, and practical implications that can be considered ineffective in preventing marginalization (research question 2). Examples are teacher preparation, the position of the assistant head responsible for special education, the Certificate of Attendance, the SU curriculum, and the lack of information and guidance on inclusion.

\section{Conclusions and Suggestions}

The article describes how special education operates in Cyprus and demonstrates that it does not contribute to integration, which is a global educational aim. The fact that the education of pupils identified as having SEN in Cyprus is regulated by unique legislation is highly relevant. However, as 
the research findings indicate, it is important that the relevant laws are revised to ensure the integration of disadvantaged pupils. We propose that the voices of pupils defined as having SEN and their parents should be listened to. The Ministry should take into account the views of these key stakeholders and use them as the basis upon which to draft a less marginalizing legal framework. Following the global trend (Byrne 2013), such legislation should have a specific section on special education, a clearly set out definition of inclusion, and stipulate how this should be pursued across schools.

SU pupils need teachers who are specially trained to respond to their needs. While a certain proportion of teachers hold postgraduate diplomas in special education or have attended relevant seminars, these qualifications are not yet part of the compulsory criteria for teaching pupils defined as having SEN. Agreeing with Symeonidou (2017), we advocate for compulsory staff training (teachers as well as managerial staff) with a view to promoting a more inclusive school environment, which should be more of a priority for the Ministry when setting out teacher training requirements.

Another suggestion is that the curriculum itself should not be disregarded. The implementation of tailored curricula targeting the personal development of all pupils would be another important change. The 2017 circular is a step in this direction, but unfortunately there are practical difficulties with it such as the creation of the class timetable. We propose that the SUs should be broken down into subgroups according to the pupils' skills, or incorporating subjects such as drama, which would improve the pupil's language skills, imagination, behavior, and overall socialization.

Another suggestion is that new institutional framework should stipulate an increase in the number of teaching periods SU pupils attend in mainstream classes so that they experience the feeling of belonging to the mainstream group. The lack of equal treatment between $\mathrm{SU}$ and mainstream pupils and the abolition of any practices that directly or indirectly emphasize pupils' differences are two additional key concerns. The Certificate of Attendance is just one example of what needs to be changed. It may be more inclusive to issue a School Leaver's Certificate or progress report, as is the case for the rest of the pupils, so as not to marginalize the SU pupils, both during and after their schooling. Despite the challenging nature of the endeavor to improve the special education system and make it more inclusive, where there is a willingness to acknowledge and change the issues at hand, then undoubtedly, there is room for substantial improvement. 


\section{References}

Ainscow, M. (2005). Developing inclusive education systems: What are the levels for change. Journal of Educational Change, 6(2), 109-124.

Ainscow, M., Booth, T., \& Dyson, A. (2006a). Improving schools - Developing inclusion, Routledge.

Ainscow, M., Booth T., \& Dyson, A. (2006b). Inclusion and the standards agenda: negotiating policy pressures in England. International Journal of Inclusive Education, 10(4-5), 295-308.

Ainscow, M., Dyson, A., Goldrick, S., \& West, M. (2016). Using collaborative inquiry to foster equity within school systems: opportunities and barriers. School Effectiveness \& School Improvement, 27(1), 7-23.

Anastasiou, D., Kauffman, J., \& Di Nuovo, S. (2015). Inclusive education in Italy: Description and reflections on full inclusion. European Journal of Special Needs, 30(4), 1-15.

Angelides, P., \& Avraamidou, L. (2010). Teaching in informal learning environments as a means for promoting inclusive education. Education, Knowledge \& Economy, 4(1), 1-14.

Beyer, L. (2001). The value of critical perspectives in teacher education. Journal of Teacher Education, 52(2), 151-163.

Blackburn, C. (2016). Early Childhood Inclusion in the United Kingdom. Infants \& Young Children 29(3), 239-246.

Brydges, C., \& Mkandawire, P. (2018). Perceptions and experiences of inclusive education among parents of children with disabilities in Lagos, Nigeria. International Journal of Inclusive Education, 24(6), 645-659.

Byrne, B. (2013). Hidden contradictions and conditionality: Conceptualisations of inclusive education in international human rights law. Disability \& Society, 28(2), 232-244.

Charalambous, C., \& Papademetriou, C. (2018). Inclusion or Exclusion? the role of special tutoring and education district committees in special secondary education units in Cyprus. International Journal of Education and Applied Research, 8(1), 30-36. Charalampous, C., \& Papademetriou, C. (2019a). Intermediate inverted Lleadership: The inclusive leader's model. International Journal of Leadership in Education, 24(3), 349-370.

Charalampous, C., \& Papademetriou, C. (2019b). Action research: The key to inclusive education in Cyprus. Journal of Pedagogy, 10(2), 3-6.

Charalampous, C., \& Papademetriou, C. (2020). Intermediate inclusive leader. Creating cooperation networks. 16th European Conference on Management Leadership and Governance, 26-27 October, Oxford UK

Commissioner for the Protection of the Rights of the Child. (2011). Commissioner for the protection of children's rights to education and training of children with disabilitiesresults of the public consultation. Nicosia.

Greenstein, A. (2014). Is this inclusion? Lessons from a very "special" unit. International Journal of Inclusive Education, 18(4), 379-391.

Haug, P. (2017). Understanding inclusive education: Ideals and reality. Scandinavian Journal of Disability Research, 19(3), 206-217. 
Damianidou, E., \& Phtiaka, H. (2018). Implementing inclusion in disabling settings: The role of teachers' attitudes and practices. International Journal of Inclusive Education, 22(10), 1078-1092.

EADSNE. (ed.) (2007) Lisbon Declaration. Available online: https://www.europeanagency.org/country-information/cyprus/national-overview/special-needs-education-within-the-education-system. Last accessed: 13/07/2016.

European Commission. (2018). Education and training monitor 2018 Greece. European Union Luxemburg

Greenberg J., \& Greenberg, C. (2016). It takes two to tango: Inclusive schooling in Hong Kong. Global Education Review, 1(1), 44 -55.

Holmberg, J., \& Jeyaprathaban, S. (2016). Effective practice in inclusive and special needs education. International Journal of Special Education, 31(1), 119-134.

Hornby, G. (2017). Inclusive special education: Development of a new theory for the education of children with special education needs and disabilities. British Journal of Special Education, 42(3), 235-255.

Kasides, D., Apostolidou E., \& Doufexi, A. (2015). The special and intercultural education in the spectrum of the inclusive philosophy, $5^{\text {th }}$ Pan-hellenic Conference of Education.

Kugelmass, J.W. (2006). Sustaining cultures of inclusion: The value and limitation of cultural analysis. European Journal of Psychology of Education, 5(1), 47-65.

Mamas, Ch. (2013). Understanding inclusion in Cyprus, European Journal of Special Needs Education, 28(4), 480-493.

McCarty, K. (2006). Full Inclusion: The Benefits and Disadvantages of Inclusive Schooling: An Overview, Azusa Pacific University.

McMaster, Ch. (2014). Elements of inclusion: Findings from the Field. KAIRARANGA. 15(1), 42-49.

Manzano-García, B., \& Fernández, M. T. (2016). The inclusive education in Europe. Universal Journal of Educational Research 4(2), 383-391.

Messiou, K. (2016). Research in the field of inclusive education: time for a rethink? International Journal of Inclusive Education, 20(12), 1-14.

Linde, R., Lemonik, A., \& Mikaila, M. (2015). Teaching progress: A critique of the grand narrative of human rights as pedagogy for marginalized students, Radical Teacher, 103, 26-36.

O'Connor, E., Yasik, A., \& Horner, S. (2016). Teachers' knowledge of special education laws: What do they know? Insights into Learning Disabilities, 13(1), 7-18.

Paliokosta, P.,, \& Blandford, S. (2010). Inclusion in school: A policy, ideology or lived experience? Similar findings in diverse school cultures. Support for Learning, 25(4), 179-186.

Papademetriou, D., \& Charalampous, C. (2020). The Role of special education paraprofessionals in the inclusion of special secondary education units students. Educational Circle, 8(1), 230-252

Phtiaka, E. (2000). From which we come and go? Cypriot state and special training. In A. Kipriotakis, (Ed), Practically auditor's special treatment. Rethymnon Crete.

Pieridou, M., \& Ptiaka H. (2013). Children with disabilities in mainstream schools: Inclusion or exclusion? Paper presented in ECER 2013: Creativity and Innovation in Educational Research. 
Priyanka, S., \& Samia, K. (2018). Barriers to inclusive education for children with special needs in schools of Jammu. The International Journal of Indian Psychology, 6(1), 93-105

Soulis, S., Georgiou, A., Dimoula, K., \& Rapti, D. (2016) Surveying inclusion in Greece: Empirical research in 2683 primary school students. International Journal of Inclusive Education, 20(7), 770-783.

Statistical Services. (2018) Education Statistics, Republic of Cyprus.

Strogilos, V. (2018) The value of differentiated instruction in the inclusion of students with special needs/disabilities in mainstream schools. SHS Web of Conferences 43,0003.

Strogilos V., \& King-Sears, M. (2018). Co-teaching is extra help and fun: Perspectives on co-teaching from middle school students and co-teachers. Journal of Research in Special Educational Needs, 18(3), 148-158.

Suleymanov, F. (2015). Issues of inclusive: Some aspects to be considered. Electronic Journal of Inclusive Education, 3(4), 2-23.

Symeonidou, S., \& Mavrou, K. (2013). Deconstructing the Greek-Cypriot new national Curriculum: To what extent are disabled children considered in the "humane and democratic school" of Cyprus? Disability \& Society, 29(2), 303-316.

Symeonidou, S. (2015). Rights of people with intellectual disability in Cyprus: Policies and practices related to greater social and educational inclusion. Journal of Policy and Practice in Intellectual Disabilities, 12(2), 120-131.

Symeonidou S. (2017a). Initial teacher education for inclusion: A review of the literature. Disability \& Society, 32 (3), 401-422.

Symeonidou, S. (2018). Disability, the arts and the curriculum: Is there common ground? European Journal of Special Needs Education. 34 (1), 50-65.

Symeonidou, S., \& Phtiaka, H. (2009) Using teachers' prior knowledge, attitudes and beliefs to develop in-service teacher education courses for inclusion. Teaching and Teacher Education, 25, 543-550.

Szeto, E., Cheng, A. \&, Sin, K. (2018). Still not inclusive? A critical analysis of changing the SENCO policy in a Chinese school community. International Journal of Inclusive Education, 24(8), 828-848.

Tilley S. (2019). The role of critical qualitative research in educational contexts: A Canadian perspective. Educar em Revista, Curitiba, Brasil, 35 (75),155-180.

Timothy, S., \& Agbenyega, J. (2018). Inclusive school leaders' perceptions on the implementation of individual Education Plans. International Journal of whole schooling, 14(1), 1-30.

Thomazet, S. (2009). From integration to inclusive education: does changing the terms improve practice? International Journal of Inclusive Education,13(6), 553-563. United Nations Educational, Scientific and Cultural Organization, EFA Global Monitoring Report 2005: The quality imperative, Paris: UNESCO Publishing.

Vasiliadou, M., \& Symeonidou, S. (2017). inclusive education to research, paper presented at the European Educational Research Association. 


\section{Authors:}

Charalampous Constantia, Ph.D.

Neapolis University Pafos

Cyprus

9 Kavala

8027 Pafos

Cyprus

Email: constantiacharalambous@gmail.com

Papademetriou Christos, Ph.D.

Neapolis University Pafos

Cyprus

9 Kavala

8027 Pafos

Cyprus

Email: c.papademetriou@nup.ac.cy 